Calancie, O., Ewing, L., Narducci, L. D., Horgan, S., \& Khalid-Khan, S. (2017). Exploring how social networking sites impact youth with anxiety: A qualitative study of Facebook stressors among adolescents with an anxiety disorder diagnosis. Cyberpsychology: Journal of Psychosocial Research on Cyberspace, 11(4), article 2. doi:

\title{
Exploring how social networking sites impact youth with anxiety: A qualitative study of Facebook stressors among adolescents with an anxiety disorder diagnosis
}

\author{
Olivia Calancie ${ }^{1,2}$, Lexi Ewing ${ }^{2}$, Laura D. Narducci ${ }^{3}$, Salinda Horgan ${ }^{4}$, \& Sarosh Khalid-Khan² \\ ${ }^{1}$ Centre for Neuroscience Studies, Queen's University, Kingston, ON, Canada \\ ${ }^{2}$ Division of Child and Adolescent Psychiatry, Queen's University, Kingston, ON, Canada \\ ${ }^{3}$ iHealth Centre, Vaughan, ON, Canada \\ ${ }^{4}$ Department of Psychiatry \& School of Rehabilitation Therapy, Queen's University, Kingston, ON, Canada
}

\begin{abstract}
Adolescents with anxiety disorders often have low self-esteem, poor problem-solving, and a strong desire to be accepted. Combined, these qualities may predispose them to experience unique stressors when using social network sites (SNSS). Focus groups of adolescent Facebook users who have a primary anxiety diagnosis uncovered narratives describing individuals' perspectives related to how Facebook can influence their anxiety. Qualitative analysis revealed six themes related to Facebook stressors: seeking approval, fearing judgment, escalating interpersonal issues, wanting privacy, negotiating self and social identity, and connecting \& disconnecting. Many participants reported a fear of receiving negative comments online and discussed strategies to avoid them, such as posting less content (i.e., comments, photographs) than their peers. Some participants described feeling positive emotions when they received a "like" from a SNS user, however, they also tended to describe these positive emotions as "false", "unreal" and "fleeting." Notably, many participants reported comparing themselves to peers on Facebook, which increased feelings of anxiety, as well as compulsive checking behaviours, such as monitoring posted content and friend lists. These findings were coupled with discussions surrounding rumination, privacy, and elevated personal conflict due in part to the public nature of Facebook. The narratives from our exploratory study suggest there are various mechanisms through which Facebook may exacerbate anxiety in adolescents who have pre-existing anxiety disorders and thereby may make them vulnerable to negative online experiences. Understanding the underlying themes of this phenomenon can aid clinicians, school staff, and parents in identifying potential stressors for anxious adolescents who use SNSs, and provide strategies around social media use for this specific patient population. Future quantitative studies are recommended to further understand the relationships between Facebook stressors and expressed anxiety in clinical populations.
\end{abstract}

Keywords: Social media; adolescence; anxiety disorders; Facebook; social networking sites

\section{Introduction}

The use of social networking sites (SNSs) among adolescents has dramatically increased since the past few years, with 51\% visiting SNSs daily, and 34\% re-visiting their SNSs several times a day (Ellison, 2007; Lenhart et al., 2015; O'Keefe \& Pearson, 2011; Rideout, 2012). SNSs refer specifically to websites where the purpose is to network and interact with other users, including websites such as Facebook, MySpace, and Twitter. In a 2015 national survey $71 \%$ of adolescents reported that they had a SNS profile and $41 \%$ used Facebook as their main SNS (Lenhart et al., 2015). 
Facebook provides not only a forum for communication via instant messaging but also allows youth to share personal content (e.g., photographs, videos, status updates, and profile posts), and to provide and receive feedback (e.g., commenting on others' shared content and reacting to content by clicking on emotions such as, "like," "love," "wow," "angry," or "sad") (Neira, Corey, \& Barber, 2014; Shaw, Timpano, Tran, \& Joormann, 2015). Additionally, Facebook allows for passive use by navigating through the site without posting or reacting to content. Passive use includes reading newsfeeds (i.e., a collection of posts shared by friends), looking through users' profiles, examining one's own profile, and reviewing old statuses or messages. Privacy settings allow users to routinely adjust who has access to, and who is blocked from viewing their shared content (Shaw et al., 2015). Through Facebook, adolescents can observe others anonymously, control their self-image, and make social comparisons with others (Ellison, 2007; Neira et al., 2014; Shaw et al., 2015). The rising use of SNSs has received considerable attention worldwide and reviews on their impact on users' mental health are mixed (Fernandez, Levinson, \& Rodebaugh, 2012; Sampasa-Kanyinga \& Lewis, 2015; Valkenburg, Koutamanis, \& Vossen, 2017; Verduyn, Ybarra, Résibois, Jonides, \& Kross, 2017). As adolescents habitually compare themselves to their peers and seek positive feedback from them, it is likely that increased use of SNS could negatively affect their emotions when they receive no or negative feedback (Harter, 1999).

Studies have examined how social media use affects well-being in healthy youth. One study found that undergraduate students who frequently used Facebook were more likely to agree with the statement, "life is unfair" (Chou \& Edge, 2012). Among Serbian high school students, the amount of time on Facebook was positively correlated with higher scores on the Beck Depression Inventory (Pantic, et al., 2012). Similarly, Labrague (2014) identified that time spent online correlated significantly with anxiety; markedly the amount of time spent on Facebook predicted higher levels of anxiety captured by the Depression, Anxiety and Stress Scale. Furthermore, research has established links between Facebook use and diminished well-being, self-esteem, and increased feelings of depression, stress, cognitive overload, and body dissatisfaction in healthy users (Chen \& Lee, 2013; Chou \& Edge, 2012; de Vries, de Graaf, \& Nikken, 2016; Kross et al., 2013). Research suggests that frequent updates from Facebook friends and the possibility of encountering negative comments may contribute to the development of negative emotions (Labrague, 2014).

Recent studies describe two important factors that may help explain how SNS use can induce stress and negative emotions. First, a study investigating physiological markers of stress associated with social media found that young Facebook users with higher numbers of Facebook friends were found to have elevated cortisol levels, when controlling for gender, age, stress, and time the endocrinological sample was collected (Morin-Major et al., 2016). Considerable literature supports that in-person social support acts as a buffer against physiological markers of stress (i.e., elevated glucocorticoid stress hormones) (Heinrichs, Baumgartner, Kirschbaum, \& Ehlert, 2003; McQuaid et al., 2016; Ponzi, Muehlenbein, Geary, \& Flinn, 2016). Thereby this study suggests that online social networks (i.e., number of Facebook friends) do not confer stress buffering the same way in-person social networks have been found to do. Similarly, a longitudinal study found that SNS users who have more online support reported higher stress and lower life satisfaction (Utz \& Breuer, 2017). Thus, online social support does not necessarily offer the benefits (i.e., reduced stress) attributed to in-person support. Secondly, a study ( $N=$ $689,003)$ conducted by Core Data Science Team at Facebook, Inc. observed that when positive expressions on an individual's Newsfeed were manipulated to become reduced, people in turn produced fewer positive posts on their own profile. Inversely, when negative expressions were reduced, people produced fewer negative posts (Kramer, Guillory, \& Hancock, 2014). This data provides compelling evidence that exposure to negative content via a personally tailored newsfeed may influence the emotional state of the user in lieu of direct, personal communication between users.

Since emotions of SNS users are influenced by Facebook Newsfeed posts, it is possible that individuals with anxiety disorders might be at a heightened risk of experiencing negative emotions due to the content on their newsfeed. It is known that adolescents with social anxiety disorder (SAD) are more likely to use SNSs rather than face-to-face interactions to garner social support (Indian \& Grieve, 2014; Weidman et al., 2012). However, Facebook use has limited ability to contribute positively to the well-being of individuals with SAD and may eventually result in increased propensity for poor outcomes and lower quality of life (Indian \& Grieve, 2014; Weidman et al., 2012). In a recent study, Shaw et al. (2015), found that greater SAD symptoms predicted increased passive Facebook use and this relationship was mediated by brooding, a known risk factor for SAD. 
Anxiety disorders, estimated to affect $10-20 \%$ of adolescents, are the most prevalent mental health disorders in youth and often predate depression (Costello, Egger, \& Angold, 2005; Essau, Lewinsohn, Olaya, \& Seeley, 2014; Merikangas et al., 2010; Sapru et al., 2016; Wittchen, Kessler, Pfister, Höfler, \& Lieb, 2000). These disorders are associated with low self-esteem, poor problem solving skills, social inhibition, and a strong desire to be accepted (Anderson, Williams, McGee, \& Silva, 1987; Khalid-Khan, Santibanez, McMicken, \& Rynn, 2007; McGee et al., 1990; Twenge, 2000). Altogether these characteristics may predispose adolescents with anxiety disorders to experience unique stressors while using Facebook. Although studies to date have identified associations between the use of SNSs and mental health issues in healthy adolescents, there is a paucity of qualitative research investigating how SNS use affects adolescents who are already diagnosed with an anxiety disorder. Qualitative methods are necessary to elaborate on quantitative studies about social media to gain insight into the breadth and depth of users' experiences (Fox \& Moreland, 2015). It is important to determine the scope of these experiences so that users, health practitioners, and teachers are aware of how SNS tools can exacerbate anxiety-related behaviours in adolescents with anxiety. Furthermore, understanding the dialogue of this topic is a crucial first step to develop successful strategies around social media use in this vulnerable patient population. To address these gaps, we designed a qualitative study to investigate the rich narratives surrounding how the negative aspects of Facebook, specifically the mechanisms through which it can contribute to anxiety, impact adolescent users with a primary anxiety disorder diagnosis.

\section{Methods}

\section{Participant Recruitment}

Participants were recruited from an outpatient child and adolescent psychiatry clinic in Kingston, Ontario. This clinic receives primary care referrals from the surrounding Kingston, Frontenac, Lennox, and Addington counties of the Southeast Local Health Integration Network (LHIN). According to the Institute for Clinical Evaluative Science Mental Health and Addictions Scorecard and Evaluation Framework (ICES MHASEF) 2015 report, the Southeast LHIN is a "high risk" area that is one of the most disadvantaged communities in Ontario, as reflected by high material deprivation and high residential instability, both of which are important risk factors associated with negative mental health outcomes in children and adolescents (Children's Mental Health Ontario, 2016).

A purposive sampling technique was used to select focus group participants. Purposive sampling is a nonprobability technique used in qualitative inquiry to strategically and purposefully select information-rich cases (Patton, 2014). This approach contrasts with the sampling techniques used in quantitative research that aim to achieve equalized representation to permit the generalization of study findings. In keeping with non-probability sampling, the aim of the current study was to provide a rich description of user experience. Thus, participants were recruited based on their degree of relevant personal experience and their ability and willingness to articulate an opinion about their experience.

We conducted three FG discussions attended by a total of 8 adolescents ( 4 females and 4 males). Our recruitment goal was to have relatively homogenous groups in terms of mental illness diagnosis and severity, with an equal balance of females and males. Eligibility criteria included being an adolescent between ages 13-18, English-speaking, with a primary diagnosis of an anxiety disorder of mild to moderate severity, and a current or recent user of Facebook. Diagnoses that would make participation in the FG difficult were excluded from the study. These diagnoses included Attention Deficit-Hyperactivity Disorder, oppositional defiant disorder, conduct disorder, intellectual disability, or severe anxiety. Participants were approached and invited to participate by child and adolescent psychiatrists at the clinic. Interested participants were screened either in-person during a clinic visit or by phone to determine eligibility. Four participants expressed interest in the study but declined participation due to not feeling comfortable speaking in a group setting or having experienced previous adverse events related to Facebook that they did not wish to share in group.

\section{Selected Participants}

A total of 8 participants attended the FG. All participants were Caucasian and ranged from 13 to 18 years with the average age being 15.5 years. All participants were from Kingston, Ontario and had a primary diagnosis of an anxiety disorder. Three participants were diagnosed with generalized anxiety disorder (GAD), 3 were diagnosed 
with social anxiety disorder, 1 was diagnosed with post-traumatic stress disorder (PTSD), and 1 was diagnosed with generalized anxiety disorder and obsessive-compulsive disorder (OCD). Majority of participants had additional mental health comorbidities, including depression, specific phobias, and Tourette's disorder.

\section{Focus Group Protocol}

The Queen's University Institutional Review Board reviewed and approved the study protocol (IRB \#6007128 SMED-087-12). The FGs were conducted in Summer 2012, with each lasting $~ 90$ minutes. Three FGs were run, one with four participants ( 3 females, 1 male) and two with two participants (two males; one male, one female). The FG groups were held in a private room within a public library outside the clinic. A co-investigator with qualitative research expertise moderated the discussions. A second-year medical student facilitated the focus group sessions. At the beginning of the group, the moderator read the consent form aloud and gave participants the opportunity to ask study-related questions before signing consent. Adult assent was collected when needed.

A semi-structured interview guide (see Appendix) was developed to guide the focus group discussion. Semistructured interview guides begin with a broad open-ended question. This question is intended to define the area of inquiry. Probing questions will direct the inquiry to different sub-areas of interest, such as 1) general use of Facebook, and 2) Facebook and anxiety. The guide is intended as a map to direct the discussion in a forward and meaningful direction. It is not intended that the moderator will rigidly follow the interview guide. Such a highly structured approach is considered inappropriate in focus group research as it may preempt the natural flow of the interaction between participants (Krueger \& Casey, 2008). The less structured approach characteristic of this form of interview helps to reveal the integrated perspectives of the participants and may assist in the discovery of new ideas (Krueger \& Casey, 2008). The interview questions focused on the personal experience and expectations of adolescent service users. Questions covered during the FG are listed on Table 1.

The FG discussion was digitally audio-recorded and transcribed verbatim then verified by listening to the original recordings. Demographic information was collected via PCS, the internal patient record system for the clinic. Participants were each compensated with a $\$ 10$ gift card. All focus group content was kept anonymous and confidential to protect the privacy of the participants.

Table 1. Focus Group Question Guide.

\section{General Use of Facebook}

Why do you use Facebook?

Can you describe when and how frequently you use Facebook?

How does Facebook help/aid you in your day-to-day life? (What does it bring to your life?)

\section{Facebook and Anxiety}

Are there aspects of Facebook that can cause you to feel increased anxiety?

Have you ever ended a session on Facebook feeling worse than when you started?

What about the session contributed to this feeling, in your opinion?

Can you describe the feeling you had? (i.e., anxiety, depression)

In your opinion, are there aspects of Facebook that can cause increased anxiety?

What are these?

What about them is anxiety provoking?

\section{Analysis}

The goal of the current study was to understand the perceptions and experiences of adolescents with anxiety disorders with respect how Facebook impacts their anxiety. Our goal was to generate an in-depth understanding of the unique experiences of this population to inform clinical practice. An interpretive, inductive analysis process was implemented. This form of analysis involves a series of analytic stages that incrementally seek to describe key components (i.e., codes) of the phenomenon of interest, and to make connections across these components (i.e., themes) to interpret relevant meaning (i.e., synthesis) (Denzin \& Lincoln, 2011). In the first 
stage of this approach, the investigator identifies key phrases and ideas that directly pertain to the research question. This was done by the interviewer (L.N) in collaboration with a colleague with qualitative expertise (S.H.). Codes were developed after an initial exploration of the data. A code manual (template) was then created to organize segments of similar or relates text for ease of interpretation and to search for confirming/disconfirming evidence of these interpretations (Crabtree \& Miller, 1999). The second level of analysis involves clustering closely related phrases and ideas into major themes. This was done by the interviewer and qualitative expert by identifying broad codes that represented similar ideas to develop larger themes. This was completed until no new themes emerged thus achieving saturation. The third level of analysis involved identifying connected meanings within and across themes (Denzin \& Lincoln, 2011).

\section{Statement of Reflexivity}

Within the context of the current study, the focus group facilitator (L.N.) had to be conscious of the potential for both positive and negative consequences stemming from the use of social media by adolescents with anxiety disorder. From a clinical perspective, it is easy to be concerned about the potential for harm that social media posits for adolescents who experience social and emotional difficulties. Social media, however, is a very large component that today's adolescents occupy. It has been shown that social media sites such as Facebook, also provide positive experiences for adolescents including greater access to social resources and enhanced social connections and learning (Valkenburg, Jochen, \& Schouten, 2006). In the current study the reflexive role of the facilitator was therefore to hold open any prior judgement of the experiences of adolescents so as truly hear the complex and sometimes nuanced perspectives and experiences of these adolescents with social media.

\section{Results}

Six themes emerged from the discussion with participants regarding their perceptions and experiences of Facebook: Seeking Approval, Fearing Judgement, Escalating Interpersonal Issues, Wanting Privacy, Negotiating Self \& Social Identity, and Connecting \& Disconnecting. Below a summary of each theme is presented. Participant quotes are followed by their focus group number (1-3), and participant ID number (1-8), so FG1, 1 = focus group 1, participant 1.

\section{Theme 1: Seeking Approval}

This theme refers to the impact of receiving versus not receiving Facebook "likes". When a Facebook user posts content (whether it be photos, videos, comments, statuses), there is an opportunity for others to "like" the posted material. When receiving a "like" from someone, particularly when receiving multiple "likes," participants reported feeling positive emotions such as excitement and confidence. However, they also tended to describe these positive emotions as "false", "unreal" and "fleeting." Some described receiving "likes" as analogous to gaining peer approval. Participants also reported that they purposely kept "liked" content visible on their profile, as evidence of their approval, even when they wanted to remove this content for other reasons.

"I had this one thing that I did where I posted myself playing a song on Facebook and it ended up getting a lot of 'likes'... this was a really long time ago and I recently watched it again and I was, like, "I really don't like this and I kind of want to take it down," but then I looked at all the 'likes', and then all of those 'likes' would be gone and nobody will see that everybody liked it" and then I thought "[t]hat's really stupid. If I don't like it, it shouldn't be there" but I still haven't taken it down because I'm kind of worried about that, that it'll all be gone" $(F G 1,1)$

Finally, participants reported being conscious of how many "likes" they receive as compared to their peers. Receiving significantly fewer "likes" than their peers caused them to question themselves and experience feelings of inadequacy.

"When you're changing your profile picture, it's like, "What are people going to think? What's going to happen? Are people going to comment or are they not going to comment?" $(F G 3,8)$ 


\section{Theme 2: Fearing Judgement}

Almost all of the participants reported that users tend to say whatever they want on Facebook and are "meaner" than they might be in person. They agreed that the lack of face-to-face interaction, and not having to deal with people's immediate verbal and nonverbal feedback, is a likely contributing factor in making users more disinhibited and perhaps more impulsive. Some adolescents shared personal experiences of being severely bullied over Facebook, many more experienced receiving "mean" comments on Facebook, and all were aware of stories of peers being cyberbullied. There was consensus over Facebook being a "cold" and "negative" environment, a place where it is routine to receive a negative comment from someone.

"I've written something in the [status] box and then I've just erased it kind of [inaudible] on my newsfeed or something, and I don't post a lot of statuses because I don't want people commenting on them, saying oh that's stupid." (FG2, 5)

“...right now there's a lot of cyberbullying and that is happening over Facebook so you don't want to, like, point out anything that could be a weakness in yourself" $(F G 1,3)$

The group reported a fear of negative comments and a desire to avoid negative comments. They stated that they wanted to appear "cool" and "liked" on Facebook. However, they described intentionally keeping a low profile online, by not posting content such as statuses or photos, so that others do not have an opportunity to judge them and post rude or hurtful comments. Some adolescents also described refraining from posting content on Facebook because they were worried that they would not receive the same positive reinforcement (i.e. the multiple "likes" and positive comments) that their peers receive. A lack of positive reinforcement may be perceived as judgment for someone with social anxiety.

"...I don't really have that same kind of eagerness to just say everything that I'm thinking or post anything, or pictures, so I always kind of feel like, "why are they so comfortable doing this and why am I not comfortable with it?" ...because they see to get so much positive reinforcement and I feel like, I'm always worried that I wouldn't. So I kind of wonder how is it possible that they can post something that people might not end up liking, but how do they end up doing it in such a way that people do. It really bothers me. It's like they have so much more confidence in this one area and I just don't have it." $(F G 1,1)$

\section{Theme 3: Escalating Interpersonal Issues}

A majority of participants agreed that Facebook can play a role in stimulating interpersonal conflicts. Some participants described Facebook as "drama central" and a place where people can go to start conflict. Some participants described a common scenario whereby fights that take place in person, or via an alternate form of communication, become escalated online. Such as when the person they conflict with writes about the argument on Facebook, often by updating their "status." This triggers others on Facebook to inquire about the situation, and subsequently the situation is 'revealed' on Facebook, placing the event in the public domain and thus opening it up for scrutiny by others.

"...the fact that she spread that instantly after the fight happened, went on Facebook and actually said something about that. It made me look bad because everyone got her side of the story first..." (FG1, 3)

"Yeah it's a negative environment sometimes to jump on Facebook so if you're already in a bad place to begin with it only makes it worse." $(F G 3,8)$

The participant group expressed frustration over the fact that a personal argument with another person can become instant social news and expressed a lack of control over how their interpersonal problems were being shared. They worried about the outcome of these situations, and their ability to cope with unforeseen consequences. Some participants described their perception that 'the truth' can become twisted through the propagation of rumours on Facebook. Accordingly, participants reported losing friends and being treated differently by peers whom they felt unfairly judged them based on what they read on Facebook. 
"...sometimes I have fights with people and usually they're not as bad [as] before I go on Facebook, and people start talking about it and it just gets all worse and then you just log off and you're, like, so mad you don't want to do anything..." (FG3, 7)

\section{Theme 4: Wanting Privacy}

This theme refers to the pressure that adolescents feel to disclose personal information on Facebook. Because the purpose of Facebook is to connect with friends and network, there is an inherent expectation within the site that users should share personal information with their Facebook friends. Participants described feeling pressured to disclose personal information on Facebook. Many of our participants reported "relationship status" as a specific area that appears to provoke anxiety. They expressed that there is an expectation that once an adolescent enters a romantic relationship with someone, they should post it on Facebook. A few participants stated that they felt that if they did not disclose their relationship status that there may be suspicion that they were experiencing relationship difficulties, or were not serious about the relationship. The need to change one's relationship "status" after a break-up was further described as anxiety provoking. A few participants shared their past break-up experiences, and indicated that when they changed their status from "in a relationship" to "single," they were inundated with comments and messages from "friends", heightening their distress. Even while in a relationship, the thought of potentially having to change their relationship status in the future caused some to worry,

"I've been in a relationship for two and a half years...our relationship has nothing to do with Facebook, but it's posted on Facebook. So I feel [that] if anything ever happened then every single person would know about it right away and that would be really hard and I find that that really worries me sometimes. It just adds to all the worry of everything else, because I don't want people, I wouldn't want people to know that and I wouldn't want to get messages from people saying, "Oh I'm so sorry. Are you okay?" (FG1, 1)

Some participants stated that they would prefer to only have people on their Facebook that they were close friends with, as they would feel more comfortable sharing things online with a smaller number of people. However, these adolescents also worried that others may perceive them to be socially inept if their Facebook friend list was smaller than most. Similarly, they worried about what others would think if they deleted them off their accounts to downsize their friend list. There is a direct conflict between the adolescent's desire to have a more private social circle online, with the peer pressures of having a large social presence which came with possibility of increased scrutiny, judgment and lack of control.

"I deleted, like, 300 people off my Facebook in that past year because I realized that a lot of them were from you know, an old school or people that I never spoke to anymore that I wouldn't want to share anything with ... I got worried that now people are going to see that I have so many less friends and they're going to think that I don't have friends, but I don't know, it makes me worry about things that I don't normally worry about." (FG1, 1)

"Every now and then I'll type a status and then I'll be like, what if somebody sees this and then thinks I'm a loser or whatever you know. So then I just erase it, when, if it was just a couple of your few close friends it wouldn't be as big a deal, but then all your friends on your Facebook potentially can see it, so then it leaves that window open for everybody." $(F G 3,8)$

\section{Theme 5: Negotiating Self \& Social Identity}

Some participants reported that when browsing through people's profiles on Facebook, they found it easy to start comparing themselves to their online peers. The situations that provoked such comparisons included viewing how attractive their peers looked in photos, seeing that peers were participating in many social activities, noticing that someone has a significantly larger number of friends than they do, or that someone receives more "likes" than they do. Participants stated that they often compare themselves negatively to their peers when on Facebook and that this causes feelings of inadequacy. 
"Yeah, it does make you feel pretty bad because even if you're looking at something that doesn't make you feel like your life isn't as good as yours, like, all of a sudden you're looking at somebody else's. It makes you automatically compare yourself to everything that's going on and you think, "I don't look that good" and you know "I have that same shirt and I don't look that good in it" or "how do they have so many pictures of themselves with so many people and why are they always at parties?"...and you know it seems like a ridiculous amount of things" $(F G 1,1)$

Some participants also reported that they currently have people on their Facebook friend list with whom they are no longer friends, including ex-boyfriends and ex-girlfriends, as well as people with whom they have had negative experiences, including people who have bullied them. These adolescents stated that viewing photos, status updates, or other online content posted by these individuals often provoked them to think and dwell on past negative experiences they had with these individuals. Because of these negative thoughts, the adolescents noted a worsening in their mood, and experiencing emotions such as anger, sadness, or nostalgia; feelings they would otherwise not have experienced had they not viewed this content online.

"The worst one for me is always, like, ex-girlfriends and their pictures with their new boyfriend and you feel awkward, because you're like I don't know if I like it, or if I say oh well that's nice, you know and then you realize, you start thinking about, like, why you two broke up and, especially if you're on bad terms but for some reason they're still on their Facebook. It brings back all that at the same time you know." $(F G 3,8)$

"Yeah, I see pictures of, like, people that have bothered me in the past and, I was just getting mad about all the things they did before." (FG2, 5)

\section{Theme 6: Connecting \& Disconnecting}

Many of the participants reported that either now or at some point in the past, they kept themselves logged into Facebook for extended periods of time. They would do this while doing other things, either on the computer, near the computer, or away from the computer. Many participants expressed that in their lives Facebook is "always on." For this reason, they found it difficult to spend quiet time alone to reflect, without the interruptions of Facebook notifications (alerts sent to mobile device about own SNS activity or others' SNS activity).

"So I feel like it's a serious pressure to be connected all the time and I think that that's the biggest thing about Facebook that's difficult. Where yeah, it makes things really convenient for everybody but it also makes there be a lot of pressure involved." (FG1, 1)

Participants stated that they often feel an urge to check Facebook and see what people might be saying. Because people can interact with personal profiles, and comment on photos and posts, the pressure to stay connected even when one desires to be disconnected, can be overwhelming. In addition, participants felt an expectation from others to respond immediately to messages and other content. The pressure for instantaneous response immediately was reported to increase feelings of distress.

"A lot of the time I've considered not having Facebook anymore but then that makes me feel almost worse than I do... even though I don't really use it, I feel so much pressure to continue to have it. If I didn't have it I just think about all the things that I wouldn't see or know about or anything like that and people would be like, "Oh I saw this on Facebook" and there's so much pressure to have it and so I feel like once you get it, you're basically stuck...it feels like your stuck... I've deactivated my Facebook page before but it never lasts very long." (FG1, 2)

Many of the participants further perceived that once content was posted on the Internet it technically could be stored indefinitely either by the website or by individual Internet users. Participants explained that even after deleting unwanted content off one's Facebook account, the many people who viewed the content would still remember what was posted. By the same token, there is an opportunity for the material to be copied and shared with others even if it has been removed from the original site. Some participants reported fearing that negative content about themselves, such as evidence of cyberbullying, embarrassing photos, or comments, 
could resurface, and cloud another person's judgment of them. Moreover, there is always the potential for the damaging material to resurface in the future.

"Normally people wouldn't see all those awful pictures from when you were, like, a teenager or they wouldn't hear about those things but it's possible for them to hear about them because they're there. Like, you know, I worry that people could see, like, all of these comments, like people calling me, like, really awful names, and not that, like, it has anything to do with me but the fact that they could see that there was all this negative activity around me, that kind of I feel like it could cloud somebody's judgment into thinking, like, "Well there's obviously a reason that somebody said that." (FG1, 1)

\section{Discussion}

We found that Facebook use can trigger multiple adverse trait characteristics that are specific to anxiety disorders that were reported to contribute to excess rumination, comparison to peers, fear of judgment, concerns over privacy, and approval seeking. Six themes emerged from our discussion of Facebook and anxiety and each theme showed a common connection between SNS use and social stressors in anxious adolescents. Our findings suggest that there are specific aspects of Facebook that can be sources of fear for anxious adolescents, or that can facilitate pre-existing maladaptive behaviours (e.g. excessively comparing oneself to others, rumination), which in turn may elevate their symptoms.

In theme 1, seeking approval, adolescents described wanting to receive positive reinforcement from their peers (i.e. 'likes'), as well as engaging in behaviours to maintain a well-received Facebook profile by keeping old posts on their profile that previously received multiple likes even if that post no longer reflected their interests. This theme speaks to how many anxious adolescents, such as those with generalized anxiety disorder (GAD), struggle with self-doubts and a negative self-image (Connolly \& Bernstein, 2007). As a way of coping with their self-doubt, adolescents with GAD frequently seek reassurance from others. For these individuals, keeping "liked" content on their profile may be their way of reassuring themselves about their self-doubts. However, gaining external reassurance is a temporary coping mechanism that may in fact serve to maintain their self-doubts and anxiety (Masi, Mucci, Favilla, Romano, \& Poli, 1999).

Reports of feelings of inadequacy due to receiving significantly fewer "likes" as compared to peers may be exaggerated in adolescents with perfectionism traits (Hewitt et al., 2002). Drs. Hewitt and Flett describe perfectionism within three dimensions: socially-prescribed, other-oriented, and self-oriented perfectionism. Socially-prescribed perfectionism is described as the individual believing that $\mathrm{s} / \mathrm{he}$ must be perfect to be valued by others (Hewitt \& Flett 1991). In their quest for perfection and acceptance from others, these individuals hold unrealistically high standards for themselves (Anthony \& McCabe, 2005). On Facebook, the perfectionistic adolescent may equate perfection with the receipt of many "likes," and thus they may place greater importance on receiving such online feedback. Alternatively, receiving fewer "likes" than anticipated may trigger powerful feelings of inadequacy in the perfectionist adolescent. In this context, the number of "likes" given by online peers serves to quantify an individual's approval within the social group.

Indeed, adolescents discussed fear of being judged by online peers within the second theme. Adolescents with social anxiety disorder worry about social interactions because they fear being scrutinized and ridiculed by others (Connolly \& Bernstein, 2007). As a coping mechanism, they tend to avoid social situations (Hazen \& Stein, 1995). However, avoiding social interactions prevents adolescents from engaging in age-appropriate experiences, and thus impairs their social functioning. By avoiding experiences that their peers are engaging in, adolescents recognize that they are behaving differently from their peers, and this may lead to feelings of guilt and low self-esteem. Despite avoiding certain situations, their fear of being judged in those situations is maintained.

With respect to Facebook, the need of participants to be liked while concurrently fearing judgment, resulted in approach-avoidance conflict. The adolescents wished to be perceived as "cool" and "liked" on Facebook, yet also wished to avoid receiving negative comments (Craighead \& Nemeroff, 2004). Participants described scenarios that involved avoiding posting content on Facebook for fear of being ridiculed. At the same time participants also recognized that they were behaving differently from most adolescents their age in this situation. As adolescents 
strive to fit in with others, the recognition by these anxious adolescents that they are behaving differently from their peers may cause increased guilt and distress and thereby further contributed to their anxiety.

An important discussion that emerged from the focus groups was the escalation of interpersonal problems over Facebook. Anxious adolescents, particularly those with anxiety disorders, tend to be very fearful of uncertain situations where they have no control (Brown, 2009). Thus, when interpersonal problems escalate over Facebook, the lack of control and the quick disintegration of their social support network may significantly increase an adolescent's anxiety. Strong social support facilitates coping with various life stressors. Past evidence supports that adolescent users of Facebook may perceive being on Facebook as a way of increasing social support (Indian \& Grieve, 2014; Rauch, Strobel, Bella, Odachowski, \& Bloom, 2014). When negative rumours get started on Facebook, however, this very support system is threatened, and may make coping with anxiety more difficult.

In the fourth theme, adolescents described wanting privacy and consequently monitoring who has access to their profile by modifying friend lists. Individuals with anxiety frequently experience a temperamental quality known as behavioural inhibition. Behavioural inhibition is a tendency to be fearful of punishment and to withdraw from unfamiliar situations (Muris \& Dietvorst, 2006). Behaviorally inhibited individuals are more reserved, thereby they express a greater need for privacy. With respect to Facebook, anxious adolescents who are also behaviourally inhibited may simply prefer more privacy online. However, the pressure they described to disclose personal information online is in direct conflict with their inherent need for privacy.

Adolescents' concerns surrounding privacy is supported by previous literature with a survey of 802 adolescents demonstrating that they manage their networks and mask information through deletion of friends or activation of 'private settings' for specific posts (Duggan \& Smith, 2014). While 52\% of surveyed adolescents reported that their online experience triggered feelings of positivity, this statistic would probably be very different in clinical samples such as ours. Anxious adolescents unable to handle online relationships, especially the ones fraught with conflict, may be prone to negative consequences, such as depression and self-harming behaviour. It is imperative that similar studies on a larger scale of SNS use in adolescent anxiety disorders be conducted.

As previously described, many anxious adolescents share perfectionistic traits (Hewitt et al., 2002). In addition to setting unrealistically high standards for themselves, perfectionists also tend to excessively compare themselves with others, and focus on the negative aspects of themselves. Comparing themselves with others in this maladaptive way leads them to take on distorted attitudes about themselves (Anthony \& McCabe, 2005). Facebook makes it very easy to view photos and information about a multitude of other people within a very short timeframe. The perfectionistic anxious adolescent is already predisposed to excessive social comparison of themselves to others. As delineated in the fifth theme, Facebook may make it even easier for users to excessively engage in social comparison by having instant access to a popularity number (i.e. number of "likes," friends, positive comments), which can further damage their distorted self-image. As many anxious individuals struggle with self-doubt and low self-esteem, profile browsing for these individuals can further reduce their overall sense of self-esteem. In anxiety disorders, there is constant worrying about events that are real or anticipated with cognitive errors and negative thought patterns. This kind of circular pattern of thinking leads to ruminations where the individual continues to dwell in the past and is not able to move forward, thereby "staying stuck". Anxiety disorders often lead to depressed mood, and ruminative thinking is most often found in this state. Moreover, in adolescence the social pressures of being popular, liked and accepted are further heightened in those with anxiety (Khalid-Khan, Santibanez, McMicken, \& Rynn, 2007).

Fox and Warber (2014) identified that anxious Facebook users tended to score high on relational uncertainty questionnaires and engage in frequent interpersonal electronic surveillance of romantic partners. Moreover, those who reported to no longer be in a relationship also commonly checked Facebook profiles of their expartners which were related to feelings of uncertainty regarding the future, that without social media, may have had a clearer ending. These findings are supported by the perspectives shared by our participants who viewed content posted by ex-partners and ex-friends and reported a worsening of their mood.

In the sixth theme, connecting \& disconnecting, adolescents expressed worries that content posted on Facebook can be stored by others and used for cyberbullying purposes in the future, even if deleted from their profile. 
International survey-based research has reported that anywhere from 9 to $24 \%$ of adolescents have experienced bullying through SNS sites, and 88\% have witnessed bullying towards SNS users (Livingstone, Haddon, Görzig, \& Olafsson 2011; Görzig, 2016; Patchin \& Hinduja, 2012; Bastiaensens et al., 2014). Cyber-bullying victimization among adolescents has been linked to negative mental health and physical health outcomes, such as depression, poor self-esteem, emotional distress, and in more extreme cases, episodes of self-harm and suicide attempts (Bastiaensens et al., 2014). Adolescents with anxiety disorders are particularly vulnerable to become victims of cyberbullying due to their heightened rejection sensitivity and self-consciousness.

Adolescents with anxiety disorders may be unable to be assertive and thus feel pressured to do things that they feel others expect of them. As social networking sites are a large component of the social sphere in adolescents' daily lives, it is likely that adolescents with anxiety disorders will use these sites even if this pressure to be linked in' exacerbates their feelings of anxiety. In 2013, Rosen and colleagues tested whether technology-related anxieties and attitudes in adolescents and adults predicted clinical symptoms related to personality disorders (Rosen, Whaling, Rab, Carrier, \& Cheever, 2013). The researchers uncovered that anxiety about not checking in with Facebook predicted a variety of symptomology, including three personality disorders, specifically narcissism, antisocial, and compulsive personality disorder.

The themes that emerged from our FGs are similar to those reported by Fox and Moreland (2015) in a qualitative study conducted with non-clinical adults investigating the negative relational and psychological aspects of Facebook. Similar to our study, the researchers uncovered themes surrounding lack of privacy and control, pressure to be connected, social comparison and jealousy, and relationship tension and conflict. The finding that these themes are also echoed by our adolescent participants (e.g., connectivity, persistence, visibility, and social feedback) suggest that Facebook use in different age groups can trigger a variety of negative emotions. However, due to the presence of anxiety disorders in these adolescents, these negative emotions are heightened and may result in negative consequences within their relationships. Many of these adolescents are desperately wanting relationships online which often they cannot seem to have in-person. Although the socially anxious adolescents prefer to pursue these online relationships compared to in-person ones, similar conflicts arise. The avoidant behaviours commonly seen in anxiety disorders are manifested in these adolescents even on SNSs. They end up experiencing "drama" when a relationship ends or there is interpersonal conflict bringing them more attention than they wanted which perhaps then results in more avoidance behaviour. As stated previously, adolescents with anxiety disorders have poor problem solving skills, low self-esteem and a strong desire to be accepted. This tends to make them approach SNSs to compare themselves to others in the quest of making themselves feel better about themselves. However, often this self-appraisal results in reinforcing their negative sense of self when they feel that others have more friends or "likes" then them. When they finally do have a relationship, they can feel accepted, however, this suddenly changes when a relationship abruptly ends leading to conflict with numerous people. This conflict can result in cyberbullying which can further damage selfesteem and reinvoke the fear of being judged and the need for privacy. This circular pattern of wanting acceptance from peers in the setting of having deficits in self-esteem, social skills and problem solving, results in anxious adolescents approaching relationships. When there is conflict in these relationships, they are unequipped to handle this and then retreat.

With the dramatic rise in the use of social media by adolescents in the past few years, understanding how SNSs may contribute to anxiety is becoming increasingly important. As previously mentioned, anxiety disorders are the most common and most treatable mental health disorders in youth (Antony, 2011; Merikangas et al., 2010). Despite this, they often go undetected and untreated (Chavira, Stein, Bailey, \& Stein, 2004). Primarily, understanding how social media may contribute to anxiety may help improve the awareness and detection of anxiety disorders. This understanding will further clinicians' ability to assess an adolescent's use of social media and understand how this interaction contributes to their anxiety and well-being. When anxious adolescents present to clinics, an important part of the clinical assessment includes information about their sleep habits, physical activity, and diet including screen time (Bagnell et al., 2011; Bernstein \& Kinlan, 1997). Greater than two hours per day of "screen time" has been found to be associated with greater psychological difficulties (Babic et al., 2017; Page, Cooper, Griew, \& Jago, 2010). If a clinician identifies that an adolescent is spending considerable amounts of time online, they may probe further about the adolescent's activities online and the adolescent's mood after using SNS sites. It would be easy to also determine the quality of the adolescent's relationships by having an in depth discussion about their online use. When clinicians are initiating conversations about online social media, the themes identified in this study may provide a helpful starting point. 


\section{Strengths}

This study is the first to explore how Facebook experiences can contribute to anxiety in adolescents with an anxiety disorder diagnosis, and is thus a timely, highly relevant study for adolescent well-being. Furthermore, the application of a qualitative research method is particularly appropriate for this research question because it allows us to explore the rich narrative of which tools of Facebook contribute to anxiety from a clinical users' perspective. This study demonstrates a homogeneous population with similar mental health diagnoses, therefore effectively capturing opinions and perspectives of our target demographic. Although some may anticipate that it would be difficult for anxious youth to recognize the specific mechanisms that contribute to their own anxiety, the results from our study indicate that all the participants shared experiences of how Facebook impacted their anxiety.

\section{Limitations}

There are several limitations to note with this study. The second and third focus groups only consisted of two adolescents each, as one participant in each group dropped out immediately before the focus group began. Focus groups are effective when participants can draw upon the experiences shared by others, so only having two individuals in a group may have limited the group discussion. Individuals with anxiety generally want to please others and have a tendency towards being agreeable, thereby it is possible that some participants refrained from contributing opinions that contradicted those made by other participants to please the focus group moderator (Russell et al., 2011). Thus, our results may be biased towards the opinions of some of the participants.

The results from our study are only representative of the individuals in the FG, which was purposefully sampled to ensure representation of a variety of anxiety disorders. We excluded adolescents with severe anxiety as well as ADHD, ODD, and learning disabilities due to concerns that they may not share their opinions or constructively participate in the group discussion. Several adolescents were interested in the study but declined participation. Some of these adolescents stated they were not comfortable with speaking in a group setting with people they did not know. In other cases, parents indicated that their child had experienced very distressing events related to Facebook, and were not comfortable with sharing their experiences in a FG. As we were not able to include the perspectives of these adolescents in our study, it is possible that there are other important Facebook stressors related to anxiety, particularly cyberbullying victimization, that we are unaware of. Furthermore, our interests were in uncovering the mechanisms that Facebook could contribute to anxiety and thus Facebook's potential impact on other areas of these adolescent lives were not examined.

It is important to recognize that while the FG were conducted in 2012, the basis of the social media landscape has changed very little; there has been a slight increase in SNS use among adolescents and Facebook has remained the top utilized SNS (Lenhart et al., 2015). However, considering slight changes in SNSs, and the evolution of adolescents, beyond what is evident in current research is still of importance.

\section{Future Studies}

To overcome some of the limitations discussed, additional focus groups on this topic should be conducted at other centres in Ontario, and across Canada. Males and females with anxiety disorders may experience Facebook and SNSs in unique ways, and so focus groups solely consisting of one gender should be conducted if different themes emerge. Similarly, adolescents of different ages (e.g. those in elementary school versus high school) may also have unique issues with respect to Facebook and SNSs, and so focus groups that include adolescents of a certain age group should also be conducted. Furthermore, specific themes that were identified in this study (e.g. seeking approval on Facebook and fear of being judged) could be further explored in quantitative studies. Examples of these include collecting physiological measures of stress (e.g., skin conductance, heart rate, cortisol levels) while adolescents with anxiety disorders navigate Facebook (e.g., upload new photographs, comment on others' profiles). It would be interesting to determine if amount of time on Facebook or type of Facebook activity (i.e., active vs. passive) selectively predicts physiological symptoms of anxiety in adolescents with anxiety disorders. This research could help inform guidelines around Facebook use 
that could be practical in youth clinical settings (e.g., community child \& youth mental health agencies, pediatrician clinics, psychiatry offices, and primary care facilities).

\section{Conclusions}

In conclusion, this study illustrates various mechanisms through which Facebook may contribute to anxiety in adolescents with anxiety disorders. The themes described in the present report will help guide future research on the impact of SNS use on anxious individuals, while providing clinicians with strategies to use when counseling these adolescents on social media use.

\section{References}

Anderson, J. C., Williams, S., McGee, R., \& Silva, P. A. (1987). DSM-III disorders in preadolescent children: Prevalence in a large sample from the general population. Archives of general psychiatry, 44, 69-76. https://doi.org/10.1001/archpsyc.1987.01800130081010

Antony, M. M. (2011). Recent advances in the treatment of anxiety disorders. Canadian Psychology/Psychologie canadienne, 52, 1-9. https://doi.org/10.1037/a0022237

Antony, M., \& McCabe, R. (2005). Perfectionism. In: A. Freeman, S. H. Felgoise, C. M. Nezu, A. M. Nezu, \& M. A. Reinecke (Eds.), Encyclopedia of Cognitive Behavior Therapy (pp. 273-277). Boston, MA: Springer.

Babic, M. J., Smith, J. J., Morgan, P. J., Eather, N., Plotnikoff, R. C., \& Lubans, D. R. (2017). Longitudinal associations between changes in screen-time and mental health outcomes in adolescents. Mental Health and Physical Activity, 12, 124-131. https://doi.org/10.1016/j.mhpa.2017.04.001

Bagnell, A., Kutcher, S., \& Garcia-Ortega, I. (2011). Identification, diagnosis \& treatment of childhood anxiety disorders: A package for first contact health providers. Kutcher and MacCarthy. Retrieved from: http://www.shared-care.ca/files/Child_Anxiety_FINAL_2012.pdf

Bastiaensens, S., Vandebosch, H., Poels, K., Van Cleemput, K., Desmet, A., \& De Bourdeaudhuij, I. (2014). Cyberbullying on social network sites. An experimental study into bystanders' behavioural intentions to help the victim or reinforce the bully. Computers in Human Behavior, 31, 259-271.

https://doi.org/10.1016/j.chb.2013.10.036

Bernstein, G. A., \& Kinlan, J. (1997). Summary of the practice parameters for the assessment and treatment of children and adolescents with anxiety disorders. Journal of the American Academy of Child \& Adolescent Psychiatry, 36, 1639-1641. https://doi.org/10.1097/00004583-199711000-00036

Brown, W. A. (2009). Massachusetts General Hospital Comprehensive Clinical Psychiatry [book review]. JAMA, 301, 2046-2051. https://doi.org/10.1001/jama.2009.720

Chavira, D. A., Stein, M. B., Bailey, K., \& Stein, M. T. (2004). Child anxiety in primary care: Prevalent but untreated. Depression and anxiety, 20, 155-164. https://doi.org/10.1002/da.20039

Chen, W., \& Lee, K. H. (2013). Sharing, liking, commenting, and distressed? The pathway between Facebook interaction and psychological distress. Cyberpsychology, Behavior, and Social Networking, 16, 728-734. https://doi.org/10.1089/cyber.2012.0272

Children's Mental Health Ontario. (2016). Report card: Promoting a seamless, coordinated system of care that puts children, youth and family first. Retrieved from http://cmho.org/documents/cmho-reportcard-2016-en.pdf

Chou, H. T. G., \& Edge, N. (2012). "They are happier and having better lives than I am": The impact of using Facebook on perceptions of others' lives. Cyberpsychology, Behavior, and Social Networking, 15, 117-121. 
Connolly, S. D., \& Bernstein, G. A. (2007). Practice parameter for the assessment and treatment of children and adolescents with anxiety disorders. Journal of the American Academy of Child \& Adolescent Psychiatry, 46, 267-283. https://doi.org/10.1097/01.chi.0000246070.23695.06

Costello, E. J., Egger, H., \& Angold, A. (2005). 10-year research update review: The epidemiology of child and adolescent psychiatric disorders: I. Methods and public health burden. Journal of the American Academy of Child \& Adolescent Psychiatry, 44, 972-986. https://doi.org/10.1097/01.chi.0000172552.41596.6f

Crabtree, B. F., \& Miller, W. L. (Eds.). (1999). Doing qualitative research. Thousand Oaks, CA: Sage Publications.

Craighead, W. E., \& Nemeroff, C. B. (Eds.). (2004). The concise Corsini encyclopedia of psychology and behavioral science. Hoboken, New Jersey: John Wiley \& Sons.

de Vries, D. A., Peter, J., de Graaf, H., \& Nikken, P. (2016). Adolescents' social network site use, peer appearancerelated feedback, and body dissatisfaction: testing a mediation model. Journal of youth and adolescence, 45, 211224. https://doi.org/10.1007/s10964-015-0266-4

Denzin, N., \& Lincoln, Y. (2011). The SAGE handbook of qualitative research. Thousand Oaks, CA: Sage Publications.

Duggan, M., \& Smith, A. (2014). Social media update 2013. Pew Research Center. Retrieved from:

http://www.pewinternet.org/2013/12/30/social-media-update-2013/

Ellison, N. B. (2007). Social network sites: Definition, history, and scholarship. Journal of Computer-Mediated Communication, 13, 210-230. https://doi.org/10.1111/j.1083-6101.2007.00393.x

Essau, C. A., Lewinsohn, P. M., Olaya, B., \& Seeley, J. R. (2014). Anxiety disorders in adolescents and psychosocial outcomes at age 30. Journal of Affective Disorders, 163, 125-132. https://doi.org/10.1016/j.jad.2013.12.033

Fernandez, K. C., Levinson, C. A., \& Rodebaugh, T. L. (2012). Profiling: Predicting social anxiety from Facebook profiles. Social Psychological and Personality Science, 3, 706-713. https://doi.org/10.1177/1948550611434967

Fox, J., \& Moreland, J. J. (2015). The dark side of social networking sites: An exploration of the relational and psychological stressors associated with Facebook use and affordances. Computers in Human Behavior, 45, 168176. https://doi.org/10.1016/j.chb.2014.11.083

Fox, J., \& Warber, K. M. (2014). Social networking sites in romantic relationships: Attachment, uncertainty, and partner surveillance on Facebook. Cyberpsychology, Behavior, and Social Networking, 17, 3-7.

https://doi.org/10.1089/cyber.2012.0667

Görzig, A. (2016). Adolescents' experience of offline and online risks: Separate and joint propensities. Computers in Human Behavior, 56, 9-13. https://doi.org/10.1016/j.chb.2015.11.006

Harter, S. (1999). The construction of the self: A developmental perspective. New York, NY: Guilford Press.

Hazen, A. L., \& Stein, M. B. (1995). Social phobia: Prevalence and clinical characteristics. Psychiatric Annals, 25, 544-549. https://doi.org/10.3928/0048-5713-19950901-08

Heinrichs, M., Baumgartner, T., Kirschbaum, C., \& Ehlert, U. (2003). Social support and oxytocin interact to suppress cortisol and subjective responses to psychosocial stress. Biological Psychiatry, 54, 1389-1398. https://doi.org/10.1016/S0006-3223(03)00465-7

Hewitt, P. L., Caelian, C. F., Flett, G. L., Sherry, S. B., Collins, L., \& Flynn, C. A. (2002). Perfectionism in children: Associations with depression, anxiety, and anger. Personality and Individual Differences, 32, 1049-1061.

https://doi.org/10.1016/S0191-8869(01)00109-X 
Hewitt, P. L., \& Flett, G. L. (1991). Perfectionism in the self and social contexts: Conceptualization, assessment, and association with psychopathology. Journal of Personality and Social Psychology, 60, 456-470.

https://doi.org/10.1037//0022-3514.60.3.456

Indian, M., \& Grieve, R. (2014). When Facebook is easier than face-to-face: Social support derived from Facebook in socially anxious individuals. Personality and Individual Differences, 59, 102-106.

https://doi.org/10.1016/j.paid.2013.11.016

Khalid-Khan, S., Santibanez, M. P., McMicken, C., \& Rynn, M. A. (2007). Social anxiety disorder in children and adolescents: Epidemiology, diagnosis, and treatment. Pediatric Drugs, 9, 227-237.

https://doi.org/10.2165/00148581-200709040-00004

Kramer, A. D., Guillory, J. E., \& Hancock, J. T. (2014). Experimental evidence of massive-scale emotional contagion through social networks. Proceedings of the National Academy of Sciences, 111, 8788-8790.

Kross, E., Verduyn, P., Demiralp, E., Park, J., Lee, D. S., Lin, N., ... \& Ybarra, O. (2013). Facebook use predicts declines in subjective well-being in young adults. PloS one, 8(8), e69841.

https://doi.org/10.1371/journal.pone.0069841

Krueger, R. A., \& Casey, M. A. (2014). Focus groups: A practical guide for applied research. Thousand Oaks, CA: Sage Publications.

Labrague L. (2014). Facebook use and adolescents' emotional states of depression, anxiety, and stress. Health Science Journal, 8, 80-89.

Lenhart, A., Duggan, M., Perrin, A., Stepler, R., Rainie, H., \& Parker, K. (2015). Teens, social media \& technology overview 2015. Pew Research Center. Retrieved from http://www.pewinternet.org/2015/04/09/teens-socialmedia-technology-2015/

Livingstone, S., Haddon, L., Görzig, A., \& Olafsson, K. (2011). Risks and safety on the internet: The perspective of European children: Full findings and policy implications from the EU Kids Online survey of 9-16 year olds and their parents in 25 countries. London, UK: EU Kids Online Network. Retrieved from http://www.Ise.ac.uk/media\%40lse/research/EUKidsOnline/EU\%20Kids\%20II\%20(2009-

11)/EUKidsOnlinelIReports/D4FullFindings.pdf

Masi, G., Mucci, M., Favilla, L., Romano, R., \& Poli, P. (1999). Symptomatology and comorbidity of generalized anxiety disorder in children and adolescents. Comprehensive Psychiatry, 40, 210-215.

https://doi.org/10.1016/S0010-440X(99)90005-6

McGee, R. O. B., Feehan, M., Williams, S., Partridge, F., Silva, P. A., \& Kelly, J. (1990). DSM-III disorders in a large sample of adolescents. Journal of the American Academy of Child \& Adolescent Psychiatry, 29, 611-619.

https://doi.org/10.1097/00004583-199007000-00016

McQuaid, R. J., McInnis, O. A., Paric, A., Al-Yawer, F., Matheson, K., \& Anisman, H. (2016). Relations between plasma oxytocin and cortisol: The stress buffering role of social support. Neurobiology of Stress, 3, 52-60. https://doi.org/10.1016/j.ynstr.2016.01.001

Merikangas, K. R., He, J. P., Burstein, M., Swanson, S. A., Avenevoli, S., Cui, L., ... \& Swendsen, J. (2010). Lifetime prevalence of mental disorders in US adolescents: Results from the National Comorbidity Survey ReplicationAdolescent Supplement (NCS-A). Journal of the American Academy of Child \& Adolescent Psychiatry, 49, 980-989. https://doi.org/10.1016/j.jaac.2010.05.017

Morin-Major, J. K., Marin, M. F., Durand, N., Wan, N., Juster, R. P., \& Lupien, S. J. (2016). Facebook behaviors associated with diurnal cortisol in adolescents: Is befriending stressful?. Psychoneuroendocrinology, 63, 238-246. https://doi.org/10.1016/j.psyneuen.2015.10.005 
Muris, P., \& Dietvorst, R. (2006). Underlying personality characteristics of behavioral inhibition in children. Child Psychiatry and Human Development, 36, 437-445. https://doi.org/10.1007/s10578-006-0014-9

Neira, B., Corey, J., \& Barber, B. L. (2014). Social networking site use: Linked to adolescents' social self-concept, self-esteem, and depressed mood. Australian Journal of Psychology, 66, 56-64. https://doi.org/10.1111/ajpy.12034

O'Keeffe, G. S., \& Clarke-Pearson, K. (2011). The impact of social media on children, adolescents, and families. Pediatrics, 127, 800-804. https://doi.org/10.1542/peds.2011-0054

Page, A. S., Cooper, A. R., Griew, P., \& Jago, R. (2010). Children's screen viewing is related to psychological difficulties irrespective of physical activity. Pediatrics, 126, e1011-e1017. https://doi.org/10.1542/peds.2010-1154

Pantic, I., Damjanovic, A., Todorovic, J., Topalovic, D., Bojovic-Jovic, D., Ristic, S., \& Pantic, S. (2012). Association between online social networking and depression in high school students: Behavioral physiology viewpoint. Psychiatria Danubina, 24, 90-93.

Patchin, J. W., \& Hinduja, S. (2012). Cyberbullying: An update and synthesis of the research. In J. W. Patchin \& S. Hinduja (Eds.), Cyberbullying prevention and response: Expert perspectives (pp. 13-35). New York, NY:

Routledge/Taylor \& Francis Group.

Patton, M. (2014). Qualitative research \& evaluation methods ( $4^{\text {th }}$ ed.). Thousand Oaks, CA: Sage Publications.

Ponzi, D., Muehlenbein, M. P., Geary, D. C., \& Flinn, M. V. (2016). Cortisol, salivary alpha-amylase and children's perceptions of their social networks. Social Neuroscience, 11, 164-174.

https://doi.org/10.1080/17470919.2015.1045988

Rauch, S. M., Strobel, C., Bella, M., Odachowski, Z., \& Bloom, C. (2014). Face to face versus Facebook: Does exposure to social networking web sites augment or attenuate physiological arousal among the socially anxious?. Cyberpsychology, Behavior, and Social Networking, 17, 187-190. https://doi.org/10.1089/cyber.2012.0498

Rideout, V. J. (2012). Social media, social life: How teens view their digital lives. Common Sense Media. Retrieved from https://www.commonsensemedia.org/research/social-media-social-life-how-teens-view-their-digital-lives

Rosen, L. D., Whaling, K., Rab, S., Carrier, L. M., \& Cheever, N. A. (2013). Is Facebook creating "iDisorders"? The link between clinical symptoms of psychiatric disorders and technology use, attitudes and anxiety. Computers in Human Behavior, 29, 1243-1254. https://doi.org/10.1016/j.chb.2012.11.012

Russell, J. J., Moskowitz, D. S., Zuroff, D. C., Bleau, P., Pinard, G., \& Young, S. N. (2011). Anxiety, emotional security and the interpersonal behavior of individuals with social anxiety disorder. Psychological Medicine, 41, 545-554. https://doi.org/10.1017/S0033291710000863

Sampasa-Kanyinga, H., \& Lewis, R. F. (2015). Frequent use of social networking sites is associated with poor psychological functioning among children and adolescents. Cyberpsychology, Behavior, and Social Networking, 18, 380-385. https://doi.org/10.1089/cyber.2015.0055

Sapru, I., Khalid-Khan, S., Choi, E., Alavi, N., Patel, A., Sutton, C., ... \& Calancie, O. G. (2016). Effectiveness of online versus live multi-family psychoeducation group therapy for children and adolescents with mood or anxiety disorders: a pilot study. International Journal of Adolescent Medicine and Health. Advanced online publication. https://doi.org/10.1515/ijamh-2016-0069

Shaw, A. M., Timpano, K. R., Tran, T. B., \& Joormann, J. (2015). Correlates of Facebook usage patterns: The relationship between passive Facebook use, social anxiety symptoms, and brooding. Computers in Human Behavior, 48, 575-580. https://doi.org/10.1016/j.chb.2015.02.003 
Twenge, J. M. (2000). The age of anxiety? The birth cohort change in anxiety and neuroticism, 1952-1993. Journal of Personality and Social Psychology, 79, 1007-21. https://doi.org/10.1037/0022-3514.79.6.1007

Utz, S., \& Breuer, J. (2017). The relationship between use of social network sites, online social support, and wellbeing: Results from a six-wave longitudinal study. Journal of Media Psychology: Theories, Methods, and Applications, 29, 115-125. https://doi.org/10.1027/1864-1105/a000222

Valkenburg, P. M., Koutamanis, M., \& Vossen, H. G. (2017). The concurrent and longitudinal relationships between adolescents' use of social network sites and their social self-esteem. Computers in Human Behavior, 76, 35-41. https://doi.org/10.1016/j.chb.2017.07.008

Valkenburg, P. M., Jochen, P., \& Schouten, A. (2006). Friend networking sites and their relationship to adolescents' well-being \& social self-esteem. CyberPsychology \& Behaviour, 9, 584-590. https://doi.org/10.1089/cpb.2006.9.584

Verduyn, P., Ybarra, O., Résibois, M., Jonides, J., \& Kross, E. (2017). Do Social Network Sites Enhance or Undermine Subjective Well-Being? A Critical Review. Social Issues and Policy Review, 11, 274-302.

Weidman, A. C., Fernandez, K. C., Levinson, C. A., Augustine, A. A., Larsen, R. J., \& Rodebaugh, T. L. (2012). Compensatory internet use among individuals higher in social anxiety and its implications for wellbeing. Personality and Individual Differences, 53, 191-195. https://doi.org/10.1016/j.paid.2012.03.003

Wittchen, H. U., Kessler, R. C., Pfister, H., Höfler, M., \& Lieb, R. (2000). Why do people with anxiety disorders become depressed? A prospective-longitudinal community study. Acta Psychiatrica Scandinavica, 102(s406), 1423. https://doi.org/10.1111/j.0065-1591.2000.acp29-03.x

\section{Correspondence to:}

Sarosh Khalid-Khan

Chair, Div. Child \& Youth Mental Health

Depts. of Psychiatry, Psychology \& CNS

Queen's University

Kingston Health Science Centre

Hotel Dieu Hospital Site

166 Brock Street; Brock 5

Kingston, ON K7L 5G2

Canada

E-mail: khalids(at)hdh.kari.net

Editorial record: First submission received on April, 21, 2017. Revisions received on November 13, 2017, and December 19, 2017. Accepted for publication on December 20, 2017. 


\section{Appendix: Focus Group Moderator Guide}

\section{Research Objective / Question?}

How can social networking sites (SNSs), specifically Facebook, contribute to anxiety in adolescents with anxiety disorders?

(Note: We are interested in the mechanisms through which Facebook can contribute to anxiety, as well as the specific contexts in which this occurs.)

\section{Logistics:}

a. Place: Private room at Kingston Public Library

b. Date: TBD

c. Time: TBD (total 2 hours)

\section{Introduction (5-10 minutes)}

a. I, [moderator], will introduce myself, and the any other facilitator present with me.

b. Explain the general purpose of the focus group and its role in research; estimate the duration of the focus group. Remind participants of potential benefits and risks of participating. Remind them that the session will be digitally recorded so that responses can be tracked, but that the record and their responses will be kept confidential and anonymous.

\section{Outline}

a. Ice-breaker (5 minutes)

b. Enjoyable aspects of Facebook (10 minutes)

c. Things you dislike about Facebook (10 minutes)

d. Viewing photos on Facebook (20 minutes)

e. Viewing friends' updates and activities on Facebook (20 minutes)

f. Use of Facebook when already anxious (20 minutes)

g. Worrying about something viewed on Facebook (20 minutes)

h. Closing and Thank you (10 minutes)

\section{Questions}

\section{a. Ice-breaker}

Go around and have everyone say their name, their favourite hobby, and when they first created their Facebook account

The purpose of having everyone say name and favourite hobby is to get people talking and comfortable with each other.

The purpose of stating when they first created their Facebook account is to get them to recognize that they have something in common (they all use Facebook). This question also gets them to start to talk about Facebook, in general terms.

\section{b. Enjoyable aspects of Facebook}

\section{"What do you like about Facebook?"}

The purpose of this question is to allow participants to talk about positive aspects of Facebook, before transitioning to more negative questions. This question also helps to keep our discussion balanced, so that we do not miss out on beneficial aspects of Facebook, just because we are interested in potential negative factors. 
c. Things you dislike about Facebook

"What are some things you don't like about Facebook?"

This question helps us transition the discussion to more negative aspects of Facebook, which will help set the stage for our main topic of anxiety.

\section{d. Viewing photos on Facebook}

"When you look at photos of people on Facebook, how do you feel?"

Prompts:

"What was it about the photo that made you feel that way?"

If participant describes that a photo made him/her anxious "What did you do after you saw the photo?" "How did you feel after you logged off Facebook"

Purpose of these questions is to understand how looking through photos of people on Facebook (people in general) might trigger negative thoughts, or feelings of anxiety. Purpose of prompt $\boldsymbol{b}$ ), is to appreciate the impact the photo had on the person; for example, did the photo trigger the adolescent to begin to ruminate about a problem or worry about something for the next couple hours.

"How do you feel when you look at photos of people that you are not friends with anymore? What about ex-boyfriends, or ex-girlfriends?"

Purpose of this question is to understand how looking through photos of someone, whom one may have had a negative experience with in the past, might trigger negative thoughts or feelings of anxiety or worry.

\section{e. Viewing friends' updates and activities on Facebook}

"How do you feel when you look through the Newsfeed on Facebook?"

"How do you feel when you read things posted by your friends?

... posted by people you aren't friends with anymore?...posted by ex-boyfriends, ex-girlfriends?" Prompts for any of the above questions:

"What was it about what you read that made you feel that way?

The purpose of these questions is to understand how reading things on Facebook might trigger negative thoughts or feelings of anxiety or worry. I am interested in the different reactions one has when reading about friends in general, and then ex-friends/ex-boyfriends/ex-girlfriends. The photos, and updates of whomever you have on Facebook can show up on your Newsfeed etc., so there is great potential to be bombarded with images/words that trigger negative memories, negative thoughts, worry, and anxiety.

f. Use of Facebook when already anxious

"Can you tell me about a time when you were worried about something, and you decided to go on Facebook?"

Prompts:

"What did you do when you logged on?"

"How did you feel while you were doing this?"

"How did you feel after you logged off Facebook?"

The purpose of this question is to identify the mechanisms by which Facebook may worsen one's pre-existing anxiety. If someone is anxious when they log onto Facebook, what activities do they engage in, and as a result does Facebook leave them feeing more or less anxious?

\section{g. Worrying about something on Facebook}

"Can you tell me about a time when you worried about something you saw on Facebook?"

Prompts:

What did you do after you saw this?

How did you feel afterwards?

Purpose of this question is to further identify the context through which Facebook can cause anxiety. Because of the direct wording of the question, this question may be more sensitive than the others, so perhaps best to leave it to the end. This question may be redundant as content from this question may be previously discussed in other questions. However, at the same time, because it is more open-ended, it gives participants a chance to discuss an experience that they didn't think of mentioning before.

h. Closing and Thank you

"Is there anything I missed that you would like to talk about?" 
"What do you think was the most important thing we discussed today?"

Purpose: we will be talking about a variety of things, so the purpose of this question is to make sure we have an accurate understanding of what part of the discussion was most relevant and important to them

"This is the first time we are doing a discussion like this. Is there anything we could do better for next time?"

Perhaps we can make this question written/anonymous - because some might be uncomfortable providing this kind of feedback to us in front of the group.

\begin{abstract}
About Authors
Olivia Calancie, MSc candidate, is a graduate student in the Centre for Neuroscience Studies at Queen's University, Canada and a researcher at Division of Child and Adolescent Psychiatry, Hotel Dieu Hospital, Canada. Her research interests include cognition of youth with borderline personality disorder traits, social media use among adolescent anxiety disorders, and EMDR.

Lexi Ewing, MA candidate, is a graduate student in the School of Applied Psychology \& Human Development at Ontario Institute for Studies in Education, University of Toronto, Canada. She studies adolescent depression and non-suicidal self-injury.
\end{abstract}

Laura Narducci, MD, is a family physician at iHealth Centre, Vaughan, Canada.

Salinda Horgan, PhD, is an adjunt professor at Department of Psychiatry \& School of Rehabilitation Therapy, Queen's University, where she serves as an expert in qualitative methods and analysis. She examines social media use and technological feasibility in clinical youth.

Sarosh Khalid-Khan, MD, is a child and adolescent psychiatrist and an associate professor at the departments of Psychiatry, Psychology, and Centre for Neuroscience Studies at Queen's University, Canada. Her research interests include healthcare quality, adolescent mood and anxiety disorders, and borderline personality disorder. 